\title{
The Future of Human Embryo Culture Media - Or Have We Reached the Ceiling?
}

\author{
Deirdre Zander-Fox ${ }^{1}$ and Michelle Lane ${ }^{2}$ \\ ${ }^{1}$ Repromed, Adelaide, $S A$, \\ ${ }^{2}$ University of Adelaide, Department of Obstetrics and Gynaecology, Adelaide, SA, \\ Australia
}

\section{Introduction}

Within the embryology laboratory one of the central components is embryo culture media. The fundamental goal/role of the laboratory and therefore the culture media has been to maintain the inherent viability of the gametes/embryos before replacement to the mother. Over the last 10-15 years there have been major advancements in this area, with culture media developing from simple salt solutions into highly complex defined media, specifically designed to reduce stress to the embryo and maintain high pregnancy rates. As a direct result of these advancements in culture media formulation and increased awareness of the contribution of QA/QC, single embryo transfer is now a realistic outcome for a majority of patients. Although the role of culture media in stress reduction and viability maintenance may have reached its ceiling, with likely only incremental increases in pregnancy rates to be made in the future, there may be a new role for culture media as a therapeutic device evolving from the goal of maintaining the inherent viability to improving the viability of the gametes and embryos.

This chapter will discuss the development of the pre-implantation embryo, the evolution of embryo culture media up until the present day and hypothesize on the future of this technology.

\section{Pre-implantation embryo physiology}

The development of embryo culture media has undergone dramatic transition since the 1950's where originally embryos were cultured in media designed to support somatic cell development (reviewed by:(Biggers 1987). Research into mammalian preimplantation embryo development has highlighted that somatic cells and the mammalian embryo are completely different in their metabolic requirements, biosynthetic pathways and also likely in their epigenome. As a result it was established several decades ago that somatic cell culture media is ill-equipped to support optimal development of the pre-implantation embryo (Bavister 1995; Brinster 1965a). This has ultimately resulted in present day culture media being designed around the stage specific nutrient requirements of the embryo as well as factoring in what is present in the natural in vivo reproductive tract environment (Gardner and Leese 1990; Leese 1988). 
However, before one can understand the progression of culture media development it is imperative to understand the complex changes that the embryo undergoes as it divides from the zygote to the blastocyst stage. Animal models are frequently utilised to study the nutrient requirements of the mammalian pre-implantation embryo and murine preimplantation development is often used as model for the human as the nutrient requirements and developmental milestones are similar.

The preimplantation embryo, defined as development from the 2 pro-nuclear $(2 \mathrm{PN})$ stage to the blastocyst, is highly complex. It is therefore easiest to consider development in two distinct stages, pre-compaction and post-compaction, although this in reality may be a significant over simplification.

\subsection{Pre-compaction stage embryo}

Initially the oocyte and early embryo are relatively quiescent cells reflecting the fact that the egg has sat dormant in the ovary for many years. Each cell undergoes a series of reductive mitotic divisions called 'cleavage', during which time the total size of the embryo does not change. Thus with each division the size of the cells, or blastomeres, is reduced, which assists in restoring the exaggerated cytoplasmic:nuclear ratio back to levels more traditionally observed in somatic cells (Johnson 1988).

At these early stages the embryo is completely reliant on its mitochondria to produce energy via oxidative phosphorylation of pyruvate (or lactate and carboxylic acids from the 2-cell stage) and cannot metabolise glucose possibly due to a block to the regulatory glycolytic enzyme phosphofruktokinase (Barbehenn et al. 1974). The early embryo is also considered to be metabolically quiescent, in that it has a low metabolic rate and has low biosynthetic activity which results in a high ATP:ADP ratio. In fact its respiratory quotient is similar to that of bone (Leese 1991; Leese and Barton 1984). The mitochondria themselves at these early stages are also quite immature with an ovoid shape and small area of inner mitochondrial membrane for energy transport. The cleavage stage embryo also appears to be more susceptible to stress exposure, as it has a limited ability to regulate against alterations in $\mathrm{pH}$, osmotic stress and reactive oxygen species due to a lack of many key homeostatic mechanisms that are routinely found in most all somatic cells (Baltz et al. 1991; Harvey et al. 1995; Lane 2001) (Figure 1).

During these early stages of development, the in vivo embryo resides in the protective environment of the oviduct which mirrors its requirements with supply of high levels of pyruvate and lower levels of glucose and protective substrates such as non- essential amino acids (Gardner et al. 1996; Leese 1988). There are also pH gradients as well as lower levels of oxygen that are conducive to an oxidative based metabolism (Fischer and Bavister 1993; Maas et al. 1977).

\subsection{Post-compaction embryo}

Following the cleavage stages, the pre-implantation embryo undergoes a change in morphology by compacting and forming a morula, at which stage the human embryo has reached the cornua of the uterus. Compaction typically occurs between the 8 and 12 cell stage in the human and involves the blastomeres flattening into one another to maximise 
cell-cell contact, resulting in the polarisation of the cells (Gallicano 2001; Ziomek and Johnson 1980). Complete activation of the embryonic genome also occurs at this time (although genomic transcription increases progressively over time with transcription as early as the 4- to 8-cell stage in the human) and there is the development of increasing transcription such that by the blastocyst stage the embryo has highly developed homeostatic systems. Once compaction has occurred the embryo now begins the process of cavitation, which results in the formation of the blastocyst. Initially the outer cells of the embryo begin to elaborate their junctional complexes, in particular ion transport systems and tight junctions in preparation for cavity formation (Watson et al. 2004). At this stage the $\mathrm{Na}+/ \mathrm{K}+-\mathrm{ATPase}$ establishes and maintains an ionic gradient across the trophectoderm, which promotes water accumulation across the epithelium due to movement of water through aquaporins (Watson et al. 2004). This, combined with the tight junctions, maintains this water in the centre of the embryo, resulting in a fluid-filled cavity. During this time the embryo undergoes cellular differentiation into two distinct cell types: inner cell mass (ICM) and trophectoderm (TE). The TE forms the outer rim of the embryo, surrounding the blastocoelic cavity, which contains blastocoelic fluid, and the ICM is located eccentrically within the blastocoelic cavity against the TE. The major difference between these two cell types is that the TE cells are now committed to certain differentiative pathways where they will eventually form extraembryonic tissue (placenta and yolk sac) (Gardner 1975), whereas the ICM is still totipotent and will eventually form the fetus as well as contributing to the yolk sac and allantois (Gardner 1975; Gardner and Rossant 1979).

Due to the high energy requirements at these later stages, the embryo now readily consumes glucose in a balance with cytoplasmic and mitochondrial metabolism and the metabolic quotient in the blastocyst reflects that commonly seen in highly proliferating tissues. The embryo resides in the uterus at this stage and the difference in the embryo itself is mirrored by the vastly different environment that the uterus provides in comparison to the oviduct with high levels of glucose and both non-essential essential amino acids and lower levels of lactate and pyruvate (Gardner et al. 1996; Gardner and Leese 1990; Leese 1988) (Figure 1).

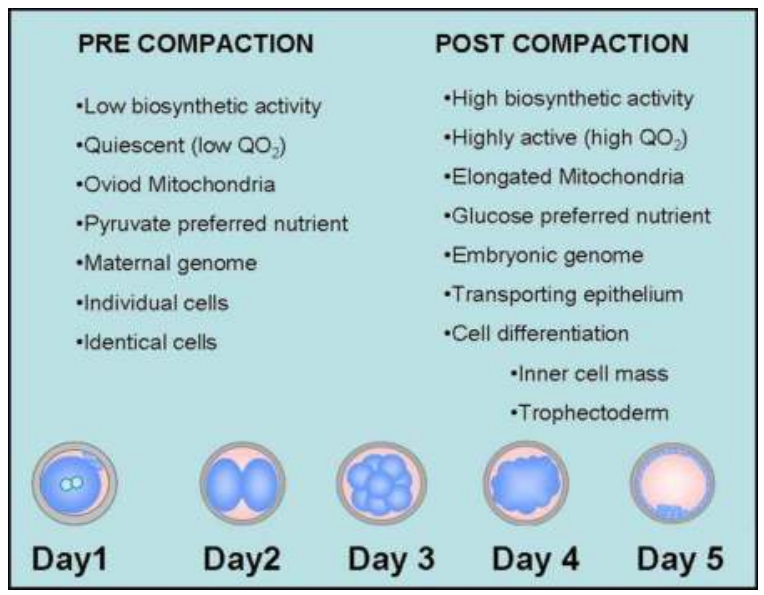

Fig. 1. Dynamics of preimplantation embryo physiology. 


\section{Embryo culture}

\subsection{Preimplantation embryo culture: the past}

The ability to culture tissue samples was pioneered in the early 1900s, and during this time the importance of using a biologically defined media was acknowledged. A biologically defined medium was beneficial in that it could be reproduced at different times and in different laboratories. It can also be varied in a controlled manner and is free of enzyme activities that may interfere with the responses being studied (Biggers 1971). The design of chemically defined media accelerated in the 1940s, as media was designed to support the growth of plant and animal cells. Following this the culture of mammalian pre-implantation embryos began in the late 1940s. At this time ill-defined culture media were used for embryo culture that primarily occurred using the rabbit as a model (Biggers 1987).

The possibility of experimentally studying the mammalian pre-implantation embryo in vitro was first realised by Whitten, who reported that 8-cell mouse embryos could develop to the blastocyst stage when cultured in a simple chemically defined media based on Krebs-Ringer bicarbonate, supplemented with glucose bovine plasma albumin, antibiotics and utilising a $\mathrm{CO}_{2}$-bicarbonate buffering system (Whitten 1956). At this point embryo stages prior to the 8cell would not grow; however, the crucial observation was made the following year that lactate was needed to support early embryo development, and, for the first time, 2-cell embryos were able to be grown to the blastocyst stage in culture (Brinster 1963; Whitten 1957). Subsequently, it was also shown that pyruvate, oxaloacetate and phosphoenolpyruvate could substitute lactate and that when used in combination, pyruvate and lactate in the media resulted in increased blastocyst yield from 2-cells, compared to when they are used alone (Brinster 1965b). These studies were of fundamental importance, as they demonstrated that the early embryo was unlike a somatic cell in that it cannot utilise glucose for development and, instead, requires a more simple sugar in the form of lactate and pyruvate. The following year the transfer of these blastocysts into surrogate mothers produced offspring that appeared outwardly normal, demonstrating that the culture environment produced viable blastocysts (McLaren and Biggers 1958).

These pioneering studies lay the foundation for the discovery of the exact substrate requirements of the mammalian embryo and assisted in overcoming the developmental blocks seen in varying stages of embryo development. It was discovered that mouse embryos from the 1-cell to 2-cell stage require pyruvate to develop, and this requirement seems to be universal among all mammalian species: therefore it is now an essential component of all media for pre-implantation embryo development (Whittingham and Biggers 1967).

During the 1960s and 1970s there were many detailed studies trying to understand more about basic embryo physiology. When pyruvate and lactate were supplied, mouse zygotes would cleave to the 2-cell stage; however, further development was blocked unless the 2cells were then transferred to explanted oviduct cultures (Whittingham and Biggers 1967) and only pyruvate would support the first cleavage division and nuclear maturation of mouse oocytes. From this it was deduced that the metabolism of the oocyte and the 1-cell embryo were virtually the same. At this point it was also discovered that the ability of the embryo to survive the culture period was highly reliant on the mouse strain. Using F1 hybrids of inbred strains it was possible to grow embryos from the 1-cell to the blastocyst in simple media of a modified salt and protein composition (Whitten and Biggers 1968). 
However, 1-cell embryos from random-bred strains would not develop and it took another 20 years of research before this problem was overcome. This research led to the discovery of the 'substrate triad' of pyruvate, lactate and glucose, as together they could support the development of some inbred mouse strain embryos from the 1-cell to the blastocyst (Bavister 1995). These substrates are still the cornerstone of most all culture media for mammalian preimplantation embryos including the human.

The seminal discovery that the human oocyte could be successfully fertilized in vitro (Edwards et al. 1969), shifted the focus to the human embryo. During this period a variety of media was used involving both simple and complex media formulations containing bovine serum albumin (BSA) or serum. As early as 1970 it was reported that the human embryo could be cultured up to the 16-cell stage in vitro (Edwards et al. 1970). Following this progress many studies were undertaken to try and support the in vitro development of species, other than the mouse and rabbit, using semi-defined serum-free media; however, this was met with limited success due to the poor knowledge of substrate requirements for each species. Most studies from this period appeared to assume that substrate requirements for all species were similar to that of the mouse and rabbit. But it has now become apparent that although some aspects are the same, each species needs to be assessed independently and the media modified depending on substrate requirements (Bavister 1995).

Although some success was found in growing embryos from a variety of species, such as monkey and cattle, these were mainly grown in complex media containing blood serum. They resulted in low blastocyst yield and did not increase the knowledge on the varying requirements of embryos from different species (Bavister 1995). It was also noted, that the majority of useful laboratory animals displayed 'blocks in development' that precluded complete pre-implantation development in culture. A variety of methods were trialled to try and overcome these blocks, such as transferring cytoplasm from non-blocking embryos into those displaying developmental blocking; however, the reason for these blocks remained unknown (Muggleton-Harris et al. 1982).

The need to overcome these developmental blocks was the focus of research during the late 1980s onwards. This was mainly due to the need to obtain complete pre-implantation development in vitro for the livestock industry, in particular using oocytes from abattoir cattle ovaries. Unlike in the human and primate, early cleavage stage embryos of most species will not survive if transferred into the uterus. Thus it is necessary to maintain in vitro development up to stages (morula and blastocyst) that are attuned with uterine transfer. Complete embryo development was also required to obtain comparative data between species, other than inbred mice and rabbits, for research purposes and also for other livestock industries.

The developmental blocks were attributed to artefacts of the culture environment, and the stage of the block appeared to be species-specific (Bavister 1995). It was also noted that the blocks were perhaps genetically derived as inbred mouse strains were able to develop from the 1-cell stage to the blastocyst; however, random-bred strains displayed the 2-cell block. Interestingly, it was discovered that these blocks in development coincided with the activation of the embryonic genome, which occurs at different stages depending on the species (Telford et al. 1990). These developmental blocks were able to be overcome by coculture; the growth of embryos alongside the growth of somatic tissue such as endothelial, 
fibroblast or ovarian cells (Allen and Wright 1984; Gandolfi and Moor 1987). Although this culturing system was able to facilitate the development of blastocysts that formed offspring after transfer, further investigations into the requirements of the embryo has resulted in the development of media systems that can facilitate blastocyst development without co-culture which eliminates the risks associated with co-culturing human embryos alongside animal somatic cells such as the transfer of bovine spongiform encephslopathy (Bavister 1995).

Many studies have shown that the environmental requirements of the pre-implantation embryo change as the embryo progresses along the female reproductive tract. Changes in morphology and ultrastructures accompany alterations in energy transport mechanisms and responsiveness to growth factors as the embryo develops and moves from the oviduct to the uterine environment (Bavister 1995). It has also been shown that changes in mitochondrial morphology accompany embryo development and that these changes may be particularly significant in relationship to the perturbed metabolism that is seen in cultured embryos (Hillman and Tasca 1969). From this it was hypothesised that perhaps the developmental blocks seen were due to inadequate energy production, as many studies have demonstrated that the addition of certain nutrients or energy substrates can overcome developmental blocks in embryo development (Brinster 1963; Whitten 1957).

Continual research into the requirements of the developing embryo led to the generation of more defined culture media, which could support the growth of a mammalian embryo from the zygote to the blastocyst stage; however, this growth was associated with decreased development and viability along with altered gene expression and perturbed mitochondrial homeostasis (Gardner and Lane 1993; Lane and Gardner 1994).

\subsection{Human embryo culture: the present}

The first 20-25 years of human IVF treatments were almost exclusively resulting from the culture of embryos to day 2 or in some cases day 3 before transfer to the uterus. The human and primate are the only 2 species where the embryo has the plasticity required for this asynchronous transfer however; this early transfer to the uterus was necessitated by an inability to grow the human embryo in culture beyond these stages at high rates.

This was a result of the lack of understanding regarding the physiology or nutrient requirements of the preimplantation human embryo. Therefore, the culture media used for the early years of human IVF were those designed for tissue culture and were either simple salt solutions or complex tissue culture media. 'Simple' media such as Tryode's or Earle's T6 medium consisted of balanced salt solutions with added carbohydrates glucose, pyruvate and lactate and were commonly supplemented with patient's serum. These media lacked many components that we now know are important for maintaining embryo physiology and health such as amino acids. Alternatively, embryos were grown in tissue culture media that were designed to support immortal cell lines in culture and were more complex containing salts supplemented with carbohydrates, amino acids, vitamins, nucleic acids and metal ions and include media such as Ham's F-10, MEM or TCM-199 (Lane 2001; Menezo et al. 1984). None of these media were designed to support embryo development and they contained many components that have subsequently been shown to be detrimental to embryo development in vitro such as high levels of glucose, metal ions and hormones (Bowden et al. 1993; Brown and Whittingham 1991; Pinsino et al. 2010; Quinn 1995; 
Takahashi and First 1992; Van Winkle and Campione 1982; Vidal and Hidalgo 1993). In fact early attempts to culture the human embryo for prolonged periods in these media resulted in low blastocyst development rates and implantation rates between 5-10\%. This contrasted with the rates of $>60 \%$ implantation following uterine lavage (Buster 1985; Buster et al. 1985).

As the human embryo shows enormous plasticity and the pregnancy rates after IVF in a variety of media formulations from the very simple to the highly complex were very similar; little research was invested into human embryo culture media formulations in the early years. However, in the early 1990's studies on animal model data began to indicate that the embryo had different nutrient requirements compared to somatic cells and that culture media for embryo development needed to be specifically designed for this purpose.

Initially a media named B2 was produced that utilised a complex array of amino acids and serum albumin followed by media designed by Quinn called HTF (human tubal fluid) that, although based on a simple base media construct, contained the same potassium concentrations seen in the human reproductive tract and resulted in improved embryo development (Menezo et al. 1984; Quinn et al. 1985). This media is still used in some laboratories to this day for human embryo culture to day 2 or day3 of development before transfer back into the uterus.

During this period, further scientific research emerged that demonstrated that the nutrient requirements of the mammalian preimplantation embryo were not only different from somatic cells but also that the requirements for the embryo change through the developmental period so that what is beneficial at one time point may cause developmental delay if given at another. One vital discovery was the switch from pyruvate-lactate metabolism in the early stages of development to glucose metabolism after activation of the embryonic genome. This, along with the issues surrounding the presence of inorganic phosphate, resulted in further modifications to culture media via the removal of phosphate and glucose, further improving embryo culture conditions (Quinn 1995). Although during this period, cleavage stage embryos were successfully grown and transferred resulting in pregnancies; these media designs still did not permit efficient development of the late stage embryo.

To try and facilitate the growth of the human blastocyst, research was conducted into the components found in oviduct and uterine fluid. These studies demonstrated that there are significant changes in the concentrations of metabolites and nutrients such as lactate, pyruvate and glucose within the tract, and that changes in these concentrations not only occur because of location but also during the stage of the menstrual cycle (Gardner and Leese 1990; Leese 1988) (Figure 2).

Furthermore, it was also discovered that amino acids play a crucial role in embryo development, and their concentrations also vary at different regions in the tract, such that a specific group of amino acids are required for early embryo development; however, late stage embryo development requires a different subset of amino acids (Bavister and Arlotto 1990; Gardner and Lane 1996; Gardner et al. 1996; Gwatkin 1969).

These studies eventually led to the design and implementation of sequential culture media, which was tailored to meet the metabolic and nutritional needs of specific stages of embryo development (Gardner 1998). This culture media design was an improvement on the current 
human culture media designs, which were single phase, and, although they were able to support limited blastocyst development, did not take into account the different nutritional needs of different stages of embryo development (Menezo et al. 1984; Quinn 1995; Quinn et al. 1985). The widespread use of sequential media has resulted in a change in clinical IVF to later stage embryos being transferred. Meta-analysis of outcomes following IVF determined that the highest rates of implantation and pregnancy resulted in the transfer of the later stage embryo to the tract compared to the earlier embryo. However, interestingly, this increase in implantation rate was dependent on the use of sequential media formulations rather than single media formulations in agreement with the studies on animal models.

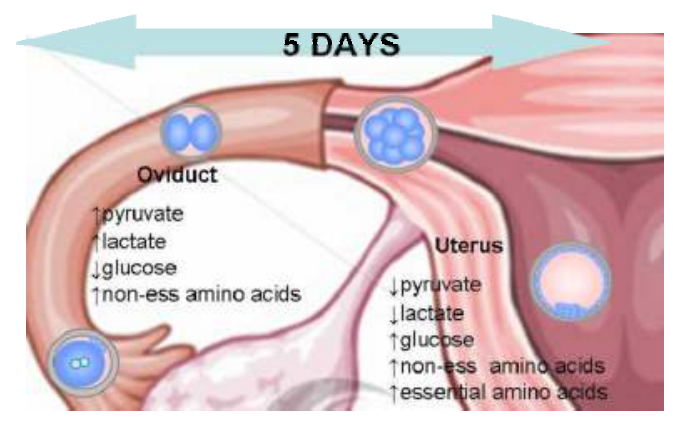

Fig. 2. Nutrient contents of the female reproductive tract and preimplantation embryo development.

\section{Culture media components}

In order to understand the different culture media available for use on the human embryo it is essential to understand the literature behind each of the key components in the formulation. The significance of this is becoming more apparent with the recent publication that different culture media may program the human embryo such that birthweight parameters are altered. Therefore, there is an increasing imperative to understand the components of the culture media and how they interact with the developing embryo.

\subsection{Nutrients}

\section{Carbohydrates}

The pre-implantation embryo relies on different energy sources at different stages of development to generate ATP. As highlighted earlier, the early stages of development appear reliant on pyruvate as an energy source (Biggers and Stern 1973; Leese and Barton 1984). Pyruvate is oxidised directly by mitochondria via oxidative phosphorylation to yield ATP, and the early embryo can utilise this mechanism only, to derive the majority of its energy.

Lactate can also be an important energy source; however, lactate cannot support the first cleavage division in the mouse embryo and causes abnormal changes in the pronuclei (Whittingham 1969). Despite this, lactate can support development from the 2-cell stage and is a regulator of pyruvate uptake. Previous studies have shown that a greater proportion of 2-cell embryos develop when both pyruvate and lactate are in the media compared to when 
either energy source is present by itself (Brinster 1965b). This is because pyruvate facilitates the conversion of lactate to pyruvate, and, conversely, lactate regulates the uptake and metabolism of pyruvate and that the regulation is based on the stage of embryo development (Biggers and Stern 1973; Lane and Gardner 2000). Studies have demonstrated that pyruvate uptake at the human pre-compaction stage is high and glucose uptake is very low; however, after compaction, a switch occurs and glucose uptake is high and pyruvate uptake decreases (Gardner and Leese 1986; Leese and Barton 1984). Together with the increased levels of these nutrients present in the oviduct, pyruvate and lactate are present in the first phase of sequential culture media in an increased amount compared to glucose (Table 1).

Glucose metabolism is also used to generate energy; however, this occurs in the later stage embryo only. Glucose is used by almost all mammalian cells as the primary energy source and so the early embryo is unique in that it lacks the ability to metabolise glucose. Experiments have demonstrated that the zygote and 2-cell mouse embryo cannot develop in the presence of glucose alone (Biggers et al. 1967; Brinster 1965a; Whitten 1957). In contrast the 8-cell mouse embryo will develop in the presence of glucose alone, and in other species, such as the rabbit, only the blastocyst stage will develop in the presence of glucose alone (Brinster and Thomson 1966; Daniel and Krishnan 1967; Whitten 1956). Glucose is taken up by the cells and converted to pyruvate by a series of reactions of the Embden-Meyerhof pathway in the cytosol. Further studies on the mouse have demonstrated that glucose is essential for the development of the blastocyst and in particular the ICM is entirely dependent on glycolysis for energy. As a result of these collective findings along with the the increased levels of glucose present in the uterus, glucose is present in the second phase of sequential culture media in an amount similar to that measured in the uterus and higher than that for the cleavage stage embryo (Table 1).

\begin{tabular}{l|ccc}
\hline & Pyruvate $(\mathbf{m M})$ & Lactate $\mathbf{( m M )}$ & Glucose $(\mathbf{m M})$ \\
\hline Oviduct & 0.32 & 10.5 & 0.5 \\
G-1 (cleavage stage) & 0.32 & 10.5 & 0.5 \\
\hline Uterus & 0.1 & 5.87 & 3.15 \\
G-2 (blastocyst stage) & 0.1 & 5.87 & 3.15 \\
\hline
\end{tabular}

Table 1. Concentration of carbohydrates in human oviduct and uterine fluid and concentration of carbohydrates in G-1 and G-2 sequential media (Gardner and Lane 1998; Gardner et al. 1996).

\section{Amino acids}

The reproductive tract also contains significant concentrations of amino acids (Fahning et al. 1967; Lane and Gardner 1997b; Miller and Schultz 1987). Furthermore, the oocyte and embryo itself maintain an endogenous pool of amino acids as well as possessing specific amino acid transporters (Van Winkle 1988). The beneficial effect of amino acids is believed to be due to their use as a metabolic substrate and also their ability to act as osmolyte and a regulator of intracellular $\mathrm{pH}$ (Edwards et al. 1998; Van Winkle et al. 1990). Amino acids also play an essential role as chelators and anti-oxidants and can regulate metabolism and cell differentiation (Gardner 1998; Lane and Gardner 1997a; Lane and Gardner 2005; Lindenbaum 1973; Liu and Foote 1995; Martin and Sutherland 2001). 
Several studies have investigated the utilisation and importance of amino acids to the embryo and, in turn, their importance in embryo culture media (Bavister and Arlotto 1990; Brinster 1971; Carney and Bavister 1987; Gardner and Lane 1996; Gardner et al. 1994; Gwatkin 1969; Kane and Bavister 1988; Kane et al. 1986; Kaye et al. 1982; Lane and Gardner 1997a; Lane and Gardner 1997b; McKiernan et al. 1995; Pinyopummintr and Bavister 1996; Schultz et al. 1981). Multiple studies have shown that amino acid transport is critical for early embryo development, even a brief exposure to media without added amino acids can be detrimental to the developing embryo by reducing development to the blastocyst stage and decreasing blastocyst cell numbers (Gardner and Lane 1996).

In particular, it has been shown that the addition of Eagle's non-essential amino acids and glutamine significantly increases development of the zygote to blastocyst stage, alleviate 2cell blocking, increases the rate of compaction and increase fetal development after transfer (Devreker et al. 1998; Gardner and Lane 1993; Gardner and Lane 1996; Lane and Gardner 1997b; McKiernan et al. 1995). In contrast zygotes cultured to the blastocyst stage in the presence of essential amino acids show a significant reduction in blastocyst cell number (Gardner and Lane 1993). Together these studies demonstrate that while non-essential amino acids and glutamine support growth from the zygote to the blastocyst stage throughout development, the presence of essential amino acids for the first 48 hours of culture have a negative impact on cellular division. Interestingly, in contrast to their lack of effect in earlier stages, essential amino acids from the 8-cell to blastocyst stage increase cleavage rates, increase development of the ICM and increase fetal development after transfer (Lane and Gardner 1997a). Therefore, non-essential amino acids are usually added to both phases of sequential media for their roles as chealtors and osmolytes and essential amino acids are added in the second phase as the metabolism of the embryo becomes more complex and more similar to that of a somatic cell.

\subsection{Ammonium}

Traditionally embryos are cultured in media at $37^{\circ} \mathrm{C}$. However, at $37^{\circ} \mathrm{C}$ components of the media such as amino acids begin to break down spontaneously forming by-products such as ammonium.

Initial studies that assessed the effect of amino acids on embryo development discovered that if embryos were cultured in the absence of amino acids, culture media renewal at 48 hours did not alter blastocyst development. In comparison, if amino acids were present in the culture media, blastocyst development was significantly increased if the culture media was renewed after both 48 and 72 hours when compared to 96 hours in the same media.

Embryo quality was also improved after media renewal, with an increase being seen in blastocyst cell number (Gardner and Lane 1993). A subsequent study demonstrated that media renewal also resulted in increased implantation and fetal weights after transfer and reduced fetal defects when comparing to embryo cultured in the same media continuously (Lane and Gardner 1994). These studies determined that spontaneous breakdown of amino acids and de-amination of amino acids by the embryos themselves resulted in a toxic buildup of ammonium. In particular, glutamine is considered to be the most volatile amino acid and is responsible for the majority of ammonium produced (Gardner and Lane 1993; Lane and Gardner 1995). However, there are now stable di-peptide forms of glutamine available 
such as alanyl-L-glutamine or glycyl-L-glutamine, which result in significantly lower levels of ammonium production (Gardner and Lane 1993; Lane and Gardner 2003).

As a result of these studies it is essential that any media containing glutamine is handled carefully. Most all media for clinical IVF have avoided this issue by including the stable dipeptide forms of glutamine.

\subsection{Macromolecules}

Serum has been used for many years to supplement somatic cell tissue culture media as it provides multiple beneficial factors including amino acids and vitamins (Bavister 1995). Initially as embryos were cultured in media developed for somatic cell culture; it is understandable that serum was also added to embryo culture. The preimplantation embryo is exposed to a variety of macromolecules such as albumin and hyaluronan in the reproductive tract, which are beneficial for embryo development, however in vivo the embryo is never exposed to serum (Leese 1988). Despite this, initial culture media designs were supplemented with whole serum which contains a large amount of unknown factors and due to its nature is highly variable in its composition. Serum has been demonstrated to be detrimental to embryo development as it causes metabolic, genetic and morphological changes in the blastocyst cultured in the presence of serum from the 1-cell stage and also results in abnormal increases in lamb offspring weight due to its presence during culture of sheep embryos (Gardner et al. 1994; Thompson et al. 1995). Aside from the significant impact serum has on embryo development, serum can be embryo toxic and each batch of serum contains differing levels of metabolites, growth factors, hormones and protein making it impossible to standardise culture conditions within a laboratory (Maurer 1992). Serum is now no longer added to human embryo culture media and instead media is often supplemented by serum albumin. Albumin is the most abundant macromolecule present in the female reproductive tract and has multiple benefits as it not only can negate the toxic effects associated with colloidal osmotic pressure but also assists in gamete and embryo manipulation by altering surface tension and preventing gametes and embryos from sticking to the culture vessel (Gardner 2008). Although serum albumin is determined to be free from biological contamination, such as HIV, before it is added to human culture media, the ability to screen for other contaminants such as prions is currently not available. This therefore makes recombinant serum albumin a more appealing choice and also allows for the elimination of small impurities such as fatty acids which often contaminate serum albumin fractions (Hanson and Ballard 1968).

Glycosaminoglycans are present at high levels in the reproductive tract fluid It has also been shown that hyaluronan levels increase in the uterus around the time of implantation, embryos express the receptor for hyaluronan (CD44) throughout development and CD44 is also expressed in the stroma of the endometrium (Behzad et al. 1994; Campbell et al. 1995; Zorn et al. 1995). Hyaluronan can also be synthesised in a pure form eliminating the issues of contamination by viral particles and prions. Studies have demonstrated that the presence of hyaluronan instead of serum albumin in mouse embryo culture media can result in increased rates of implantation and that exposure of blastocysts to hyaluronan prior to transfer also increases implantation rates (Gardner et al. 1999). Hyaluronan also increases cryotolerance in multiple species and assists in the maintenance of embryo ultrastructure (Lane et al. 2003; Palasz et al. 2006). Further, transfer of embryos in a medium with hyaluronan has been demonstrated to increase implantation rates in the human (Bontekoe et al. 2009). 


\subsection{Growth factors}

During preimplantation development, the embryo is exposed to a variety of growth factors and cytokines present within the female reproductive tract (Hardy and Spanos 2002). These factors mediate cross-talk between the embryo and maternal tissue to facilitate development and implantation and are produced by both the embryo and also the maternal environment therefore posing the question of: should embryo culture media be supplemented with growth factors and cytokines?

Insulin and insulin like growth factor (IGF) ligands have received considerable research attention as they are involved in cell proliferation and glucose transport. Insulin and IGF are present at the 8-cell stage murine embryo and have also been detected in the reproductive tract (Henemyre and Markoff 1999; Heyner et al. 1989). Insulin and IGF improve in vitro maturation outcomes in a variety of species and the addition of insulin and IGF ligands to culture media increases cell proliferation, blastocyst development rates and increases ICM cell numbers in the mouse (Gardner and Kaye 1991; Guler et al. 2000; Harvey and Kaye 1992; Kaye and Gardner 1999; Makarevich and Markkula 2002). In addition the presence of IGF can also protect against the negative effects of oxidative stress (Kurzawa et al. 2002). Due to this insulin is now a component of some culture media available for human IVF.

Two growth factors that have received considerable attention are TGF- $\beta$ (transforming growth factor beta) and GM-CSF (granulocyte-macrophage colony stimulating factor); however there are many more possible candidates which are being investigated such as EGF (epidermal growth factor), LIF (leukaemia inhibitory factor) and IGF (insulin-like growth factor).

TGF- $\beta$ belongs to a large gene family and has multiple roles within the cell including enhancing cell growth, differentiation and formation of extracellular matrix (Paria and Dey 1990). TGF- $\beta$ has been demonstrated to be produced by preimplantation mouse embryos suggesting a possible role via autocrine and paracrine mechanisms (Rappolee et al. 1988; Slager et al. 1991). Another study has demonstrated that the late stage embryo (8-cell to blastocyst) has the ability to bind radiolabeled TGF- $\beta$ demonstrating that the embryo has the potential to react to TGF- $\beta$ signalling and the addition of TGF- $\beta$ to embryo culture media increases development to the blastocyst stage (Paria and Dey 1990; Paria et al. 1992).

GM-CSF is involved in cellular proliferation and differentiation and is produced by epithelial cells of the oviduct and uterus (Robertson et al. 1992; Zhao and Chegini 1994). The GM-CSF receptor is expressed by both cell lineages of the blastocyst and embryos exposed to GM-CSF in culture have increased blastocyst development and increases glucose transport and hatching rates (Robertson et al. 2001; Sjoblom et al. 1999). Exposure of mouse embryos to GM-CSF in culture also resulted in the suppression of stress response genes such as Hspa5 and Bax (Chin et al. 2009). Together these results suggest that both TGF- $\beta$ and GMCSF may play an important role in embryo development and differentiation, and the addition of these growth factors to human embryo culture media may improve blastocyst development and ultimately implantation rates.

That being said, studies have also demonstrated the possible inhibitory effects of growth factors on embryo development where the addition of multiple growth factors to embryo culture media from the 2-cell stage, including both mouse and human recombinant-CSF, significantly inhibited blastocyst development (Hill et al. 1987). Therefore great care must be taken when adding growth factors as what is beneficial at one stage may be inhibitory at another. 


\section{The future of human culture media: from maintenance to rescue}

To date the philosophy of the laboratory and therefore function of the culture medium has been in maintaining the inherent viability of the gamete/embryo until they are returned to the female reproductive tract. This philosophy has worked well such that results from around the world indicate that more than $85 \%$ of women under the age of 35 should expect to conceive with a single embryo transfer within 12-18 months of IVF treatment. It is therefore likely that, in these patient groups where there are healthy gametes with a high inherent viability, the culture media that we currently use functions at a level that is suitable, providing maximal outcomes for these patients.

However, what about the increasing patient groups where the inherent viability of the gametes that we receive maybe reduced or low? For example in western society there has been a shift toward delaying childbearing for a variety of social reasons. Concomitantly there has been an increase in the number of women of advanced maternal age seeking assisted reproductive technologies to artificially compensate for this loss of fecundity. Previous research has demonstrated that significant perturbations occur in oocytes as maternal age increases. For example, increases in reactive oxygen species (ROS) in oocytes has been linked to increasing maternal age and it has been hypothesised that oocytes may be particularly susceptible to ROS damage while dormant in the ovary, potentially damaging lipids, proteins and DNA(Eichenlaub-Ritter et al. 2010; Miquel and Fleming 1984; Tarin et al. 1998a; Tarin 1996). This increase in ROS is proposed to be due to 'leaky mitochondria' as high energy electrons are transported along the electron transport chain and are leaked into the cytoplasm resulting the the formation of ROS such as superoxide anion $\left(\mathrm{O}^{2-}\right)$, hydrogen peroxide $\left(\mathrm{H}_{2} \mathrm{O}_{2}\right)$ and hydroxyl free radical $(\mathrm{OH} \cdot)$ which can then damage the oocyte (Tarin et al. 1998a; Tarin et al. 1998b).

It is these older patients that become repeat cyclers and where the current technology is frequently unable to provide the 'holy grail' of a viable embryo for transfer. This presents a large knowledge gap in our treatment strategies and it is therefore not unreasonable to suggest that this will become the focus of advancements in the future.

\subsection{Repair of mitochondrial function: quenching ROS}

Perturbations to mitochondrial function and increased ROS levels are associated with the onset of many diseases including Parkinson's, Huntington's and Alzheimer's and is also linked to the aging process. Due to this fact, mitochondrial therapeutics are being investigated to try and improve mitochondrial function and possibly repair the damage associated with aging and disease (Chen ; Hoekstra et al. ; Pashkow 2011). Similarly in the oocyte and embryo one of the common observations after either in vivo (e.g. aging) or in vitro stress is a reduction in mitochondrial function that is often observed before any changes in developmental measures can be seen. These perturbations in mitochondrial activity and the balance of cytoplasmic and mitochondrial metabolism are associated with reduced rates of development and also reduced implantation and fetal development in animal models. One of the main causes of this decline in mitochondrial function is likely the production of ROS.

ROS can be produced by a variety of metabolic pathways however in the embryo is primarily produced by oxidative phosphorylation (OXPHOS) as a by-product of 
metabolism. Oxidative stress is responsible for damage to lipids by inducing peroxidation (Nasr-Esfahani et al. 1990), protein inactivation via inducing the formation of disulphide bonds (Gutteridge and Halliwell 1989) and DNA strand breaks (Lopes et al. 1998). In particular mitochondrial DNA (mDNA) is particularly susceptible to ROS damage due to its lack of histones and, due to the fact that mDNA encodes vital subunits for the OXPHOS pathway, this can result in metabolic dysfunction (Guerin et al. 2001). As the oocyte and embryo relies so heavily on mitochondrial metabolism, damage to mitochondrial DNA may result in decreased generation of ATP, damaging the oocyte and resultant embryo (Eichenlaub-Ritter et al. 2004). ATP levels in oocytes and embryos are positively correlated with the proportion of embryos that reach the blastocyst stage and has been linked to their implantation potential (Quinn and Wales 1973; Van Blerkom et al. 1995).

Aging in many tissue types has been linked to increased levels of oxidative stress, in particular increased maternal age has been associated with decreased mitochondrial membrane potential and activity, increased prevelance of mDNA deletions and a decline in antioxidant levels within the oocyte. Therefore it has been hypothesised that the decline in oocyte viability seen with advanced maternal age may be due to oxidative stress (Keefe et al. 1995; Tarin 1996; Wilding et al. 2001; Wilding et al. 2003). In addition advanced maternal age has also been associated with increased rates of aneuploidy, in particular trisomy, which may increase in frequency due to decreased energy generation which results in impaired chromosome alignment and spindle activity (Wilding et al. 2005). Decreased mitochondrial membrane potential has also been linked to increased rates of chaotic mosaicism, further supporting this hypothesis (Wilding et al. 2003). Together this information demonstrates that increased ROS coupled with decreasing levels of antioxidant can result in large amount of cellular damage, cumulatively resulting in decreased oocyte and embryo viability (Figure 3).



Fig. 3. Proposed model of cellular damage and the link to decreased implantation the in the aged oocyte.

In vivo the oocyte and embryo are protected from ROS by oxygen scavangers or metalbinding proteins, such as albumin or transferrin, present in oviduct and uterine fluid (Guerin et al. 2001). The oocyte and embryo also contain numerous compounds which have 
antioxidant function including pyruvate, cysteamine, taurine and hypotaurine, glutathione (GSH) and Co-enzyme Q10 as well as enzymatic mechanisms such as superoxide dismutase (SOD) and catalase (Bentinger et al. 2007; El Mouatassim et al. 1999; Gardiner and Reed 1994; Guerin and Menezo 1995; Guyader-Joly et al. 1998; Lapointe et al. 1998).

Animal studies have demonstrated that supplementing culture media with SOD or catalase increases blastocyst development rates and assists in overcoming the 2-cell block often seen in the mouse however the addition of these enzymes is very expensive and not always effective (Li et al. 1993; Noda et al. 1991; Payne et al. 1992).

Vitamins are another important source of antioxidants and have been demonstrated to decrease hydrogen peroxide $\left(\mathrm{H}_{2} \mathrm{O}_{2}\right)$ levels in sperm when semen preparation media is supplemented with Vitamin C and E (Donnelly et al. 1999). Vitamin supplementation has also been demonstrated to be of benefit when administered orally as in the aged mouse model, oral supplementation with vitamins $C$ and $E$ reduces age associated perturbations in segregation of chromosomes and spindle arrangement (Tarin et al. 1998b).

Similarly some amino acids can also act as antioxidants for example hypotaurine has been demonstrated to neutralise hydroxyl radicals therefore preventing sperm lipid peroxidation (Alvarez and Storey 1983). During this process hypotaurine is converted to taurine which then has further antioxidant effects by neutralising cytotoxic aldehydes. Hypotaurine has been added to culture media demonstrating beneficial effects on blastocyst development in a variety of species including the human (Barnett and Bavister 1992; Devreker and Hardy 1997; Dumoulin et al. 1992) and is frequently seen in bovine embryo culture media.

However despite their obvious benefit, antioxidants must be used with care as often they can have a negative impact on development; in particular thiols such as CSH have been shown to decrease blastocyst development at concentrations greater than $250 \mu \mathrm{m} / 1$ and that a delicate balance in redox state must be maintained as significant alterations may lead to cell cycle arrest and embryo death (Guyader-Joly et al. 1998; Liu et al. 1999).

As oxidative stress may be in part responsible for the aging of the oocyte, the addition of antioxidants to culture media may be the next step in trying to rescue mitochondrial function and therefore ATP production. Today's culture media formulations do contain some antioxidants, in particular pyruvate, and low levels of amino acids, however the current concentrations of these components has most often been established based on their function as a nutrient and not as an antioxidant.

One factor, Coenzyme Q10 (CoQ10) is not only an antioxidant, but is also part of the respiratory chain complex. CoQ10 is primarily found in its reduced form of ubiquinol, thereby having the ability to oxidise free radicals, and levels have been shown to be decreased in the aged cell (Bentinger et al. 2007; Sohal and Forster 2007). The oral supplementation of CoQ10 has been used successfully in the treatment of hypertension, congenative heart failure and Parkinson's, all of which are associated with mitochondrial dysfunction (Langsjoen and Langsjoen 2008; Rosenfeldt et al. 2003; Winkler-Stuck et al. 2004). In addition oral supplementation of CoQ10 to rats decreases the incidence of mitochondrial complex I deletion often associated with aging and increases mitochondrial activity in the oocyte up to the level seen in young control mice (Bentov et al. 2009; Ochoa et al. 2011). 
Due to being water insoluble, CoQ10 is difficult to use in culture media, however CoQ10 has been added to bovine in vitro culture (via nano-particle technology) and subsequently improved cleavage rates, blastocyst development and cell numbers as well as ATP production (Stojkovic et al. 1999). In addition synthetic analogues such as Co-enzyme Q2 (CoQ2) and idebnenone have been developed for use in vitro and have been shown to reduce rates of lipid peroxidation as well as stimulating mitochondrial electron flow and increasing oxidation of Complex II (Briere et al. 2004; Imada et al. 2008). It is therefore possible that the addition of components, such as CoQ10, CoQ2 and idebenone to culture media, may not only assist in quenching ROS, but also may stimulate OXPHOS resulting in increased mitochondrial function and ultimately improved oocyte viability.

\subsection{Future gazing: customised culture media}

Evidence of the metabolic changes that occurs with age have demonstrated that the aged oocyte is very different to an oocyte obtained from a young woman, however increased maternal age is not the only condition that alters the oocyte. The increasing rates of obesity within the Western population and the negative effect obesity has on fecundity has lead to increasing rates of obese women accessing assisted reproductive treatment. Obesity is associated with decreased conception rates (even in those women with regular ovulation) and increased rates of miscarriage possibly indicative of an effect of obesity on periconception events such oocyte and embryo quality and viability (Robker 2008; van der Steeg et al. 2008). The follicular environment of obese women is different to women with normal BMI as follicular fluid from obese women contains increased levels of insulin, lactate, triglycerides and C-reactive protein, all of which may contribute to the decreased fecundity seen in obese women (Robker et al. 2009). In animal models, mice fed a high fat diet exhibit increased levels of intracellular lipid within the oocyte and reduced mitochondrial membrane potential as well as decreased blastocyst development and decreased blastocyst cell number compared to control fed mice (Igosheva et al. 2010; Minge et al. 2008; Wu et al. 2010). This therefore demonstrates that, as with advanced maternal age, the oocytes from obese women are different to oocytes from women of normal weight. This example can also be applied to altered maternal diet (such as high/low protein intake or under-nutrition), diabetes and smoking as well as pathologies such as polycystic ovarian syndrome, all of which have been linked to altered oocyte and embryo physiology and or molecular make up (Depa-Martynow et al. 2006; Kwong et al. 2000; Ludwig et al. 1999; McEvoy et al. 1997; Qiao and Feng 2011; Shiloh et al. 2004; Wynn and Wynn 1988).

This therefore poses the question: If not all oocytes/embryos are created equal, then why do we treat them as such?

The environment in which the oocyte is grown can have a significant impact on the genetic, epigenetic and molecular and metabolic makeup of the embryo, therefore should customised culture media be designed to factor in these differences and try and rescue the inherent viability of the oocyte and embryo by reversing the perturbations induced by suboptimal environmental conditions. In addition, although this chapter has not covered the topic of sperm, it would be remiss to neglect the contribution of sperm health to embryo viability. The impact of paternal age, weight and health can also impact greatly on the ability of the embryo to implant and develop into healthy offspring and as IVF culture media possibly moves from maintenance to repair, sperm health should also be considered 
and factored into gamete culture media design. It is these concepts that are likely to drive changes in culture media formulations in the future.

\section{Conclusion}

Since embryo culture was first introduced in the 1940's, research has demonstrated that the mammalian embryo is unique in its development, as unlike a somatic cell, it requires specific nutrients at differing stages as it develops from a relatively quiescent single cell into the highly active blastocyst. As a result, embryo culture media formulations have also developed in the hope of providing the necessary nutrient requirements when they are needed by the embryo. However since the development of sequential culture media systems, innovation into culture media design has remained somewhat static. This begs the question of: have we reached the ceiling of culture media design?

Present day media formulation are primarily focused on maintenance of oocyte viability however with the decreased oocyte viability associated with advanced maternal age, obesity as well as a range of other in vivo stresses such as under-nutrition, smoking and pathologies such as endometriosis, it is possible that current culture conditions need to move to being therapeutic in design to try and reverse the damage induced by these conditions.

However before this can be achieved we must first understand what 'goes wrong' in the oocyte and the embryo before we can implement a strategy to restore function and improve viability. Increasing our knowledge as to how the molecular function of the egg contributes to the viability of the embryo is essential for IVF culture media design to move into the next phase of oocyte and embryo repair.

\section{References}

Allen RL, Wright RW, Jr. (1984) In vitro development of porcine embryos in coculture with endometrial cell monolayers or culture supernatants. J Anim Sci 59, 1657-61.

Alvarez JG, Storey BT (1983) Taurine, hypotaurine, epinephrine and albumin inhibit lipid peroxidation in rabbit spermatozoa and protect against loss of motility. Biol Reprod 29, 548-55.

Baltz JM, Biggers JD, Lechene C (1991) Two-cell stage mouse embryos appear to lack mechanisms for alleviating intracellular acid loads. J Biol Chem 266, 6052-7.

Barbehenn EK, Wales RG, Lowry OH (1974) The explanation for the blockade of glycolysis in early mouse embryos. Proc Natl Acad Sci U S A 71, 1056-60.

Barnett DK, Bavister BD (1992) Hypotaurine requirement for in vitro development of golden hamster one-cell embryos into morulae and blastocysts, and production of term offspring from in vitro-fertilized ova. Biol Reprod 47, 297-304.

Bavister BD (1995) Culture of preimplantation mammalian embryos: Facts and Artifacts. Hum Reprod Update 1, 91-148.

Bavister BD, Arlotto T (1990) Influence of single amino acids on the development of hamster one-cell embryos in vitro. Mol Reprod Dev 25, 45-51.

Behzad F, Seif MW, Campbell S, Aplin JD (1994) Expression of two isoforms of CD44 in human endometrium. Biol Reprod 51, 739-47.

Bentinger M, Brismar K, Dallner G (2007) The antioxidant role of coenzyme Q. Mitochondrion 7 Suppl, S41-50. 
Bentov Y, Esfandiari N, Burstein E, Casper RF (2009) The use of mitochondrial nutrients to improve the outcome of infertility treatment in older patients. Fertil Steril 93, 272-5.

Biggers J (1987) Pioneering mammalian embryo culture. In 'The Mammalian Preimplantation Embryo'. (Ed. BD Bavister) pp. 1-22. (Plenum Publishing: New York)

Biggers JD, Stern S (1973) Metabolism of the preimplantation mammalian embryo. Adv Reprod Physiol 6, 1-59.

Biggers JD, Whitten, W.K. and Whittingham, D.G (1971) The culture of mouse embryos in vitro. In 'Methods in Mammalian Embryology'. (Ed. JC Daniel). (W.H.Freeman: San Francisco)

Biggers JD, Whittingham DG, Donahue RP (1967) The pattern of energy metabolism in the mouse oocyte and zygote. Proc Natl Acad Sci U S A 58, 560-7.

Bontekoe S, Blake D, Heineman MJ, Williams EC, Johnson N (2009) Adherence compounds in embryo transfer media for assisted reproductive technologies. Cochrane Database Syst Rev, CD007421.

Bowden HC, Tesh JM, Ross FW (1993) Effects of female sex hormones in whole embryo culture. Toxicol In Vitro 7, 799-802.

Briere JJ, Schlemmer D, Chretien D, Rustin P (2004) Quinone analogues regulate mitochondrial substrate competitive oxidation. Biochem Biophys Res Commun 316, 1138-42.

Brinster RL (1963) A Method for in Vitro Cultivation of Mouse Ova from Two-Cell to Blastocyst. Exp Cell Res 32, 205-8.

Brinster RL (1965a) Studies on the Development of Mouse Embryos in Vitro. Ii. The Effect of Energy Source. J Exp Zool 158, 59-68.

Brinster RL (1965b) Studies on the development of mouse embryos in vitro. IV. Interaction of energy sources. J Reprod Fertil 10, 227-40.

Brinster RL (1971) Uptake and incorporation of amino acids by the preimplantation mouse embryo. J Reprod Fertil 27, 329-38.

Brinster RL, Thomson JL (1966) Development of eight-cell mouse embryos in vitro. Exp Cell Res 42, 308-15.

Brown JJ, Whittingham DG (1991) The roles of pyruvate, lactate and glucose during preimplantation development of embryos from F1 hybrid mice in vitro. Development 112, 99-105.

Buster JE (1985) Embryo donation by uterine flushing and embryo transfer. Clin Obstet Gynaecol 12, 815-24.

Buster JE, Bustillo M, Rodi IA, Cohen SW, Hamilton M, Simon JA, Thorneycroft IH, Marshall JR (1985) Biologic and morphologic development of donated human ova recovered by nonsurgical uterine lavage. 153, 211-7.

Campbell S, Swann HR, Aplin JD, Seif MW, Kimber SJ, Elstein M (1995) CD44 is expressed throughout pre-implantation human embryo development. Hum Reprod 10, 425-30.

Carney EW, Bavister BD (1987) Stimulatory and inhibitory effects of amino acids on the development of hamster eight-cell embryos in vitro. J In Vitro Fert Embryo Transf 4, 162-7.

Chen CM Mitochondrial dysfunction, metabolic deficits, and increased oxidative stress in Huntington's disease. Chang Gung Med J 34, 135-52.

Chin PY, Macpherson AM, Thompson JG, Lane M, Robertson SA (2009) Stress response genes are suppressed in mouse preimplantation embryos by granulocytemacrophage colony-stimulating factor (GM-CSF). Hum Reprod 24, 2997-3009. 
Daniel JC, Jr., Krishnan RS (1967) Amino acid requirements for growth of the rabbit blastocyst in vitro. J Cell Physiol 70, 155-60.

Depa-Martynow M, Jedrzejczak P, Taszarek-Hauke G, Josiak M, Pawelczyk L (2006) [The impact of cigarette smoking on oocytes and embryos quality during in vitro fertilization program]. Przegl Lek 63, 838-40.

Devreker F, Hardy K (1997) Effects of glutamine and taurine on preimplantation development and cleavage of mouse embryos in vitro. Biol Reprod 57, 921-8.

Devreker F, Winston RM, Hardy K (1998) Glutamine improves human preimplantation development in vitro. Fertil Steril 69, 293-9.

Donnelly ET, McClure N, Lewis SE (1999) The effect of ascorbate and alpha-tocopherol supplementation in vitro on DNA integrity and hydrogen peroxide-induced DNA damage in human spermatozoa. Mutagenesis 14, 505-12.

Dumoulin JC, Evers JL, Bras M, Pieters MH, Geraedts JP (1992) Positive effect of taurine on preimplantation development of mouse embryos in vitro. J Reprod Fertil 94, 373-80.

Edwards LJ, Williams DA, Gardner DK (1998) Intracellular pH of the mouse preimplantation embryo: amino acids act as buffers of intracellular $\mathrm{pH}$. Hum Reprod 13, 3441-8.

Edwards RG, Bavister BD, Steptoe PC (1969) Early stages of fertilization in vitro of human oocytes matured in vitro. Nature 221, 632-5.

Edwards RG, Steptoe PC, Purdy JM (1970) Fertilization and cleavage in vitro of preovulator human oocytes. Nature 227, 1307-9.

Eichenlaub-Ritter U, Vogt E, Yin H, Gosden R (2004) Spindles, mitochondria and redox potential in ageing oocytes. Reprod Biomed Online 8, 45-58.

Eichenlaub-Ritter U, Wieczorek M, Luke S, Seidel T (2010) Age related changes in mitochondrial function and new approaches to study redox regulation in mammalian oocytes in response to age or maturation conditions. Mitochondrion 11, 783-96.

El Mouatassim S, Guerin P, Menezo Y (1999) Expression of genes encoding antioxidant enzymes in human and mouse oocytes during the final stages of maturation. $\mathrm{Mol}$ Hum Reprod 5, 720-5.

Fahning ML, Schultz RH, Graham EF (1967) The free amino acid content of uterine fluids and blood serum in the cow. J Reprod Fertil 13, 229-36.

Fischer B, Bavister BD (1993) Oxygen tension in the oviduct and uterus of rhesus monkeys, hamsters and rabbits. J Reprod Fertil 99, 673-9.

Gallicano GI (2001) Composition, regulation, and function of the cytoskeleton in mammalian eggs and embryos. Front Biosci 6, D1089-108.

Gandolfi F, Moor RM (1987) Stimulation of early embryonic development in the sheep by co-culture with oviduct epithelial cells. J Reprod Fertil 81, 23-8.

Gardiner CS, Reed DJ (1994) Status of glutathione during oxidant-induced oxidative stress in the preimplantation mouse embryo. Biol Reprod 51, 1307-14.

Gardner DK (1998) Changes in requirements and utilization of nutrients during mammalian preimplantation embryo development and their significance in embryo culture. Theriogenology 49, 83-102.

Gardner DK (2008) Dissection of culture media for embryos: the most important and less important components and characteristics. Reprod Fertil Dev 20, 9-18.

Gardner DK, Lane M (1993) Amino acids and ammonium regulate mouse embryo development in culture. Biol Reprod 48, 377-85. 
Gardner DK, Lane M (1996) Alleviation of the '2-cell block' and development to the blastocyst of CF1 mouse embryos: role of amino acids, EDTA and physical parameters. Hum Reprod 11, 2703-12.

Gardner DK, Lane M (1998) Culture of viable human blastocysts in defined sequential serum-free media. Hum Reprod 13 Suppl 3, 148-59; discussion 160.

Gardner DK, Lane M, Calderon I, Leeton J (1996) Environment of the preimplantation human embryo in vivo: metabolite analysis of oviduct and uterine fluids and metabolism of cumulus cells. Fertil Steril 65, 349-53.

Gardner DK, Lane M, Spitzer A, Batt PA (1994) Enhanced rates of cleavage and development for sheep zygotes cultured to the blastocyst stage in vitro in the absence of serum and somatic cells: amino acids, vitamins, and culturing embryos in groups stimulate development. Biol Reprod 50, 390-400.

Gardner DK, Leese HJ (1986) Non-invasive measurement of nutrient uptake by single cultured pre-implantation mouse embryos. Hum Reprod 1, 25-7.

Gardner DK, Leese HJ (1990) Concentrations of nutrients in mouse oviduct fluid and their effects on embryo development and metabolism in vitro. J Reprod Fertil 88, 361-8.

Gardner DK, Rodriegez-Martinez H, Lane M (1999) Fetal development after transfer is increased by replacing protein with the glycosaminoglycan hyaluronan for mouse embryo culture and transfer. Hum Reprod 14, 2575-80.

Gardner HG, Kaye PL (1991) Insulin increases cell numbers and morphological development in mouse pre-implantation embryos in vitro. Reprod Fertil Dev 3, 79-91.

Gardner RL, Papaioannou, V.E (1975) Differentiation in the trophectoderm and inner cell mass. In 'The early development of mammals'. (Ed. ME Balls, Wild, A.E) pp. 107132. (Cambridge Uni Press: London)

Gardner RL, Rossant J (1979) Investigation of the fate of 4-5 day post-coitum mouse inner cell mass cells by blastocyst injection. J Embryol Exp Morphol 52, 141-52.

Guerin P, El Mouatassim S, Menezo Y (2001) Oxidative stress and protection against reactive oxygen species in the pre-implantation embryo and its surroundings. Hum Reprod Update 7, 175-89.

Guerin P, Menezo Y (1995) Hypotaurine and taurine in gamete and embryo environments: de novo synthesis via the cysteine sulfinic acid pathway in oviduct cells. Zygote 3, 333-43.

Guler A, Poulin N, Mermillod P, Terqui M, Cognie Y (2000) Effect of growth factors, EGF and IGF-I, and estradiol on in vitro maturation of sheep oocytes. Theriogenology 54, 209-18.

Gutteridge JM, Halliwell B (1989) Iron toxicity and oxygen radicals. Baillieres Clin Haematol 2, 195-256.

Guyader-Joly C, Guerin P, Renard JP, Guillaud J, Ponchon S, Menezo Y (1998) Precursors of taurine in female genital tract: effects on developmental capacity of bovine embryo produced in vitro. Amino Acids 15, 27-42.

Gwatkin RB (1969) Nutritional requirements for post-blastocyst development in the mouse. Amino acids and protein in the uterus during implantation. Int J Fertil 14, 101-5.

Hanson RW, Ballard FJ (1968) Citrate, pyruvate, and lactate contaminants of commercial serum albumin. J Lipid Res 9, 667-8.

Hardy K, Spanos S (2002) Growth factor expression and function in the human and mouse preimplantation embryo. J Endocrinol 172, 221-36. 
Harvey MB, Arcellana-Panlilio MY, Zhang X, Schultz GA, Watson AJ (1995) Expression of genes encoding antioxidant enzymes in preimplantation mouse and cow embryos and primary bovine oviduct cultures employed for embryo coculture. Biol Reprod $53,532-40$.

Harvey MB, Kaye PL (1992) Insulin-like growth factor-1 stimulates growth of mouse preimplantation embryos in vitro. Mol Reprod Dev 31, 195-9.

Henemyre C, Markoff E (1999) Expression of insulin-like growth factor binding protein-4, insulin-like growth factor-I receptor, and insulin-like growth factor-I in the mouse uterus throughout the estrous cycle. Mol Reprod Dev 52, 350-9.

Heyner S, Smith RM, Schultz GA (1989) Temporally regulated expression of insulin and insulin-like growth factors and their receptors in early mammalian development. Bioessays 11, 171-6.

Hill JA, Haimovici F, Anderson DJ (1987) Products of activated lymphocytes and macrophages inhibit mouse embryo development in vitro. J Immunol 139, 2250-4.

Hillman N, Tasca RJ (1969) Ultrastructural and autoradiographic studies of mouse cleavage stages. Am J Anat 126, 151-173.

Hoekstra JG, Montine KS, Zhang J, Montine TJ Mitochondrial therapeutics in Alzheimer's disease and Parkinson's disease. Alzheimers Res Ther 3, 21.

Igosheva N, Abramov AY, Poston L, Eckert JJ, Fleming TP, Duchen MR, McConnell J (2010) Maternal diet-induced obesity alters mitochondrial activity and redox status in mouse oocytes and zygotes. PLoS One 5, e10074.

Imada I, Sato EF, Kira Y, Inoue M (2008) Effect of CoQ homologues on reactive oxygen generation by mitochondria. Biofactors 32, 41-8.

Johnson M, Everitt, B. (1988) 'Essential Reproduction.' (Blackwell Scientific Publications: Oxford)

Kane MT, Bavister BD (1988) Protein-free culture medium containing polyvinylalcohol, vitamins, and amino acids supports development of eight-cell hamster embryos to hatching blastocysts. J Exp Zool 247, 183-7.

Kane MT, Carney EW, Bavister BD (1986) Vitamins and amino acids stimulate hamster blastocysts to hatch in vitro. J Exp Zool 239, 429-32.

Kaye PL, Gardner HG (1999) Preimplantation access to maternal insulin and albumin increases fetal growth rate in mice. Hum Reprod 14, 3052-9.

Kaye PL, Schultz GA, Johnson MH, Pratt HP, Church RB (1982) Amino acid transport and exchange in preimplantation mouse embryos. J Reprod Fertil 65, 367-80.

Keefe DL, Niven-Fairchild T, Powell S, Buradagunta S (1995) Mitochondrial deoxyribonucleic acid deletions in oocytes and reproductive aging in women. Fertil Steril 64, 577-83.

Kurzawa R, Glabowski W, Baczkowski T, Brelik P (2002) Evaluation of mouse preimplantation embryos exposed to oxidative stress cultured with insulin-like growth factor I and II, epidermal growth factor, insulin, transferrin and selenium. Reprod Biol 2, 143-62.

Kwong WY, Wild AE, Roberts P, Willis AC, Fleming TP (2000) Maternal undernutrition during the preimplantation period of rat development causes blastocyst abnormalities and programming of postnatal hypertension. Development 127, 4195202.

Lane M (2001) Mechanisms for managing cellular and homeostatic stress in vitro. Theriogenology 55, 225-36. 
Lane M, Gardner DK (1994) Increase in postimplantation development of cultured mouse embryos by amino acids and induction of fetal retardation and exencephaly by ammonium ions. J Reprod Fertil 102, 305-12.

Lane M, Gardner DK (1995) Removal of embryo-toxic ammonium from the culture medium by in situ enzymatic conversion to glutamate. J Exp Zool 271, 356-63.

Lane M, Gardner DK (1997a) Differential regulation of mouse embryo development and viability by amino acids. J Reprod Fertil 109, 153-64.

Lane M, Gardner DK (1997b) Nonessential amino acids and glutamine decrease the time of the first three cleavage divisions and increase compaction of mouse zygotes in vitro. J Assist Reprod Genet 14, 398-403.

Lane M, Gardner DK (2000) Lactate regulates pyruvate uptake and metabolism in the preimplantation mouse embryo. Biol Reprod 62, 16-22.

Lane M, Gardner DK (2003) Ammonium induces aberrant blastocyst differentiation, metabolism, $\mathrm{pH}$ regulation, gene expression and subsequently alters fetal development in the mouse. Biol Reprod 69, 1109-17.

Lane M, Gardner DK (2005) Mitochondrial malate-aspartate shuttle regulates mouse embryo nutrient consumption. J Biol Chem 280, 18361-7.

Lane M, Maybach JM, Hooper K, Hasler JF, Gardner DK (2003) Cryo-survival and development of bovine blastocysts are enhanced by culture with recombinant albumin and hyaluronan. Mol Reprod Dev 64, 70-8.

Langsjoen PH, Langsjoen AM (2008) Supplemental ubiquinol in patients with advanced congestive heart failure. Biofactors 32, 119-28.

Lapointe S, Sullivan R, Sirard MA (1998) Binding of a bovine oviductal fluid catalase to mammalian spermatozoa. Biol Reprod 58, 747-53.

Leese HJ (1988) The formation and function of oviduct fluid. J Reprod Fertil 82, 843-56.

Leese HJ (1991) Metabolism of the preimplantation mammalian embryo. Oxf Rev Reprod Biol $13,35-72$.

Leese HJ, Barton AM (1984) Pyruvate and glucose uptake by mouse ova and preimplantation embryos. J Reprod Fertil 72, 9-13.

Li J, Foote RH, Simkin M (1993) Development of rabbit zygotes cultured in protein-free medium with catalase, taurine, or superoxide dismutase. Biol Reprod 49, 33-7.

Lindenbaum A (1973) A survey of naturally occurring chelating ligands. Adv Exp Med Biol 40, 67-77.

Liu L, Trimarchi JR, Keefe DL (1999) Thiol oxidation-induced embryonic cell death in mice is prevented by the antioxidant dithiothreitol. Biol Reprod 61, 1162-9.

Liu Z, Foote RH (1995) Effects of amino acids on the development of in-vitro matured/invitro fertilization bovine embryos in a simple protein-free medium. Hum Reprod 10, 2985-91.

Lopes S, Jurisicova A, Sun JG, Casper RF (1998) Reactive oxygen species: potential cause for DNA fragmentation in human spermatozoa. Hum Reprod 13, 896-900.

Ludwig M, Finas DF, al-Hasani S, Diedrich K, Ortmann O (1999) Oocyte quality and treatment outcome in intracytoplasmic sperm injection cycles of polycystic ovarian syndrome patients. Hum Reprod 14, 354-8.

Maas DH, Storey BT, Mastroianni L, Jr. (1977) Hydrogen ion and carbon dioxide content of the oviductal fluid of the rhesus monkey (Macaca mulatta). Fertil Steril 28, 981-5.

Makarevich AV, Markkula M (2002) Apoptosis and cell proliferation potential of bovine embryos stimulated with insulin-like growth factor I during in vitro maturation and culture. Biol Reprod 66, 386-92. 
Martin PM, Sutherland AE (2001) Exogenous amino acids regulate trophectoderm differentiation in the mouse blastocyst through an mTOR-dependent pathway. Dev Biol 240, 182-93.

Maurer HR (1992) Towards serum-free, chemically defined media for mammalian cell culture. In 'Animal Cell Culture: A Practical Approach'. (Ed. RI Freshney) pp. 15-46. (Oxford University Press: Oxford)

McEvoy TG, Robinson JJ, Aitken RP, Findlay PA, Robertson IS (1997) Dietary excesses of urea influence the viability and metabolism of preimplantation sheep embryos and may affect fetal growth among survivors. Anim Reprod Sci 47, 71-90.

McKiernan SH, Clayton MK, Bavister BD (1995) Analysis of stimulatory and inhibitory amino acids for development of hamster one-cell embryos in vitro. Mol Reprod Dev 42, 188-99.

McLaren, Biggers JD (1958) Successful development and birth of mice cultivated in vitro as early as early embryos. Nature $182,877-8$.

Menezo Y, Testart J, Perrone D (1984) Serum is not necessary in human in vitro fertilization, early embryo culture, and transfer. Fertil Steril 42, 750-5.

Miller JG, Schultz GA (1987) Amino acid content of preimplantation rabbit embryos and fluids of the reproductive tract. Biol Reprod 36, 125-9.

Minge CE, Bennett BD, Norman RJ, Robker RL (2008) Peroxisome proliferator-activated receptor-gamma agonist rosiglitazone reverses the adverse effects of diet-induced obesity on oocyte quality. Endocrinology 149, 2646-56.

Miquel J, Fleming JE (1984) A two-step hypothesis on the mechanisms of in vitro cell aging: cell differentiation followed by intrinsic mitochondrial mutagenesis. Exp Gerontol 19, 31-6.

Muggleton-Harris A, Whittingham DG, Wilson L (1982) Cytoplasmic control of preimplantation development in vitro in the mouse. Nature 299, 460-2.

Nasr-Esfahani MH, Aitken JR, Johnson MH (1990) Hydrogen peroxide levels in mouse oocytes and early cleavage stage embryos developed in vitro or in vivo. Development 109, 501-7.

Noda Y, Matsumoto H, Umaoka Y, Tatsumi K, Kishi J, Mori T (1991) Involvement of superoxide radicals in the mouse two-cell block. Mol Reprod Dev 28, 356-60.

Ochoa JJ, Pamplona R, et al. (2011) Age-related changes in brain mitochondrial DNA deletion and oxidative stress are differentially modulated by dietary fat type and coenzyme Q. Free Radic Biol Med 50, 1053-64.

Palasz AT, Rodriguez-Martinez H, Beltran-Brena P, Perez-Garnelo S, Martinez MF, Gutierrez-Adan A, De la Fuente J (2006) Effects of hyaluronan, BSA, and serum on bovine embryo in vitro development, ultrastructure, and gene expression patterns. Mol Reprod Dev 73, 1503-11.

Paria BC, Dey SK (1990) Preimplantation embryo development in vitro: cooperative interactions among embryos and role of growth factors. Proc Natl Acad Sci U S A 87, 4756-60.

Paria BC, Jones KL, Flanders KC, Dey SK (1992) Localization and binding of transforming growth factor-beta isoforms in mouse preimplantation embryos and in delayed and activated blastocysts. Dev Biol 151, 91-104.

Pashkow FJ (2011) Oxidative Stress and Inflammation in Heart Disease: Do Antioxidants Have a Role in Treatment and/or Prevention? Int J Inflam 2011, 514623. 
Payne SR, Munday R, Thompson JG (1992) Addition of superoxide dismutase and catalase does not necessarily overcome developmental retardation of one-cell mouse embryos during in-vitro culture. Reprod Fertil Dev 4, 167-74.

Pinsino A, Turturici G, Sconzo G, Geraci F (2010) Rapid changes in heat-shock cognate 70 levels, heat-shock cognate phosphorylation state, heat-shock transcription factor, and metal transcription factor activity levels in response to heavy metal exposure during sea urchin embryonic development. Ecotoxicology 20, 246-54.

Pinyopummintr T, Bavister BD (1996) Effects of amino acids on development in vitro of cleavage-stage bovine embryos into blastocysts. Reprod Fertil Dev 8, 835-41.

Qiao J, Feng HL (2011) Extra- and intra-ovarian factors in polycystic ovary syndrome: impact on oocyte maturation and embryo developmental competence. Hum Reprod Update 17, 17-33.

Quinn P (1995) Enhanced results in mouse and human embryo culture using a modified human tubal fluid medium lacking glucose and phosphate. J Assist Reprod Genet 12, 97-105.

Quinn P, Kerin JF, Warnes GM (1985) Improved pregnancy rate in human in vitro fertilization with the use of a medium based on the composition of human tubal fluid. Fertil Steril 44, 493-8.

Quinn P, Wales RG (1973) The relationships between the ATP content of preimplantation mouse embryos and their development in vitro during culture. J Reprod Fertil 35, 301-9.

Rappolee DA, Brenner CA, Schultz R, Mark D, Werb Z (1988) Developmental expression of PDGF, TGF-alpha, and TGF-beta genes in preimplantation mouse embryos. Science 241, 1823-5.

Robertson SA, Mayrhofer G, Seamark RF (1992) Uterine epithelial cells synthesize granulocyte-macrophage colony-stimulating factor and interleukin-6 in pregnant and nonpregnant mice. Biol Reprod 46, 1069-79.

Robertson SA, Sjoblom C, Jasper MJ, Norman RJ, Seamark RF (2001) Granulocytemacrophage colony-stimulating factor promotes glucose transport and blastomere viability in murine preimplantation embryos. Biol Reprod 64, 1206-15.

Robker RL (2008) Evidence that obesity alters the quality of oocytes and embryos. Pathophysiology 15, 115-21.

Robker RL, Akison LK, Bennett BD, Thrupp PN, Chura LR, Russell DL, Lane M, Norman RJ (2009) Obese women exhibit differences in ovarian metabolites, hormones, and gene expression compared with moderate-weight women. J Clin Endocrinol Metab 94, 1533-40.

Rosenfeldt F, Hilton D, Pepe S, Krum H (2003) Systematic review of effect of coenzyme Q10 in physical exercise, hypertension and heart failure. Biofactors 18, 91-100.

Schultz GA, Kaye PL, McKay DJ, Johnson MH (1981) Endogenous amino acid pool sizes in mouse eggs and preimplantation embryos. J Reprod Fertil 61, 387-93.

Shiloh H, Lahav-Baratz S, Koifman M, Ishai D, Bidder D, Weiner-Meganzi Z, Dirnfeld M (2004) The impact of cigarette smoking on zona pellucida thickness of oocytes and embryos prior to transfer into the uterine cavity. Hum Reprod 19, 157-9.

Sjoblom C, Wikland M, Robertson SA (1999) Granulocyte-macrophage colony-stimulating factor promotes human blastocyst development in vitro. Hum Reprod 14, 3069-76.

Slager HG, Lawson KA, van den Eijnden-van Raaij AJ, de Laat SW, Mummery CL (1991) Differential localization of TGF-beta 2 in mouse preimplantation and early postimplantation development. Dev Biol 145, 205-18. 
Sohal RS, Forster MJ (2007) Coenzyme Q, oxidative stress and aging. Mitochondrion 7 Suppl, S103-11.

Stojkovic M, Westesen K, Zakhartchenko V, Stojkovic P, Boxhammer K, Wolf E (1999) Coenzyme $\mathrm{Q}(10)$ in submicron-sized dispersion improves development, hatching, cell proliferation, and adenosine triphosphate content of in vitro-produced bovine embryos. Biol Reprod 61, 541-7.

Takahashi Y, First NL (1992) In vitro development of bovine one-cell embryos: Influence of glucose, lactate, pyruvate, amino acids and vitamins. Theriogenology 37, 963-78.

Tarin J, Ten J, Vendrell FJ, de Oliveira MN, Cano A (1998a) Effects of maternal ageing and dietary antioxidant supplementation on ovulation, fertilisation and embryo development in vitro in the mouse. Reprod Nutr Dev 38, 499-508.

Tarin JJ (1996) Potential effects of age-associated oxidative stress on mammalian oocytes/embryos. Mol Hum Reprod 2, 717-24.

Tarin JJ, Vendrell FJ, Ten J, Cano A (1998b) Antioxidant therapy counteracts the disturbing effects of diamide and maternal ageing on meiotic division and chromosomal segregation in mouse oocytes. Mol Hum Reprod 4, 281-8.

Telford NA, Watson AJ, Schultz GA (1990) Transition from maternal to embryonic control in early mammalian development: a comparison of several species. Mol Reprod Dev 26, 90-100.

Thompson JG, Gardner DK, Pugh PA, McMillan WH, Tervit HR (1995) Lamb birth weight is affected by culture system utilized during in vitro pre-elongation development of ovine embryos. Biol Reprod 53, 1385-91.

Van Blerkom J, Davis PW, Lee J (1995) ATP content of human oocytes and developmental potential and outcome after in-vitro fertilization and embryo transfer. Hum Reprod $10,415-24$.

van der Steeg JW, Steures P, et al. (2008) Obesity affects spontaneous pregnancy chances in subfertile, ovulatory women. Hum Reprod 23, 324-8.

Van Winkle LJ (1988) Amino acid transport in developing animal oocytes and early conceptuses. Biochim Biophys Acta 947, 173-208.

Van Winkle LJ, Campione AL (1982) Toxic effects of $\mathrm{Zn++}$ and $\mathrm{Cu}++$ on mouse blastocysts in vitro. Experientia 38, 354-6.

Van Winkle LJ, Haghighat N, Campione AL (1990) Glycine protects preimplantation mouse conceptuses from a detrimental effect on development of the inorganic ions in oviductal fluid. J Exp Zool 253, 215-9.

Vidal F, Hidalgo J (1993) Effect of zinc and copper on preimplantation mouse embryo development in vitro and metallothionein levels. Zygote 1, 225-9.

Watson AJ, Natale DR, Barcroft LC (2004) Molecular regulation of blastocyst formation. Anim Reprod Sci 82-83, 583-92.

Whitten WK (1956) Culture of tubal mouse ova. Nature 177, 96.

Whitten WK (1957) Culture of tubal ova. Nature 179, 1081-2.

Whitten WK, Biggers JD (1968) Complete development in vitro of the pre-implantation stages of the mouse in a simple chemically defined medium. J Reprod Fertil 17, 399401.

Whittingham DG (1969) The failure of lactate and phosphoenolpyruvate to support development of the mouse zygote in vitro. Biol Reprod 1, 381-6.

Whittingham DG, Biggers JD (1967) Fallopian tube and early cleavage in the mouse. Nature $213,942-3$. 
Wilding M, Dale B, Marino M, di Matteo L, Alviggi C, Pisaturo ML, Lombardi L, De Placido G (2001) Mitochondrial aggregation patterns and activity in human oocytes and preimplantation embryos. Hum Reprod 16, 909-17.

Wilding M, De Placido G, De Matteo L, Marino M, Alviggi C, Dale B (2003) Chaotic mosaicism in human preimplantation embryos is correlated with a low mitochondrial membrane potential. Fertil Steril 79, 340-6.

Wilding M, Di Matteo L, Dale B (2005) The maternal age effect: a hypothesis based on oxidative phosphorylation. Zygote 13, 317-23.

Winkler-Stuck K, Wiedemann FR, Wallesch CW, Kunz WS (2004) Effect of coenzyme Q10 on the mitochondrial function of skin fibroblasts from Parkinson patients. J Neurol Sci 220, 41-8.

Wu LL, Dunning KR, Yang X, Russell DL, Lane M, Norman RJ, Robker RL (2010) High-fat diet causes lipotoxicity responses in cumulus-oocyte complexes and decreased fertilization rates. Endocrinology 151, 5438-45.

Wynn M, Wynn A (1988) Nutrition around conception and the prevention of low birthweight. Nutr Health 6, 37-52.

Zhao Y, Chegini N (1994) Human fallopian tube expresses granulocyte-macrophage colony stimulating factor (GM-CSF) and GM-CSF alpha and beta receptors and contain immunoreactive GM-CSF protein. J Clin Endocrinol Metab 79, 662-5.

Ziomek CA, Johnson MH (1980) Cell surface interaction induces polarization of mouse 8-cell blastomeres at compaction. Cell 21, 935-42.

Zorn TM, Pinhal MA, Nader HB, Carvalho JJ, Abrahamsohn PA, Dietrich CP (1995) Biosynthesis of glycosaminoglycans in the endometrium during the initial stages of pregnancy of the mouse. Cell Mol Biol (Noisy-le-grand) 41, 97-106. 


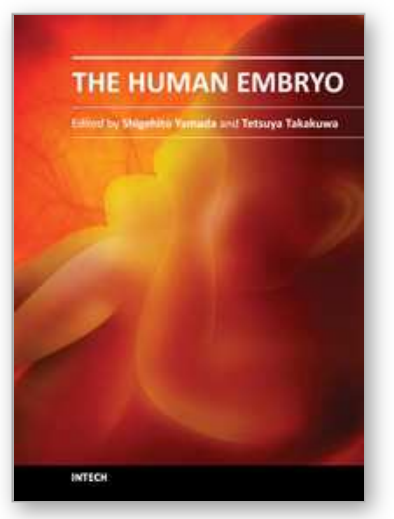

\author{
The Human Embryo \\ Edited by Dr. Shigehito Yamada
}

ISBN 978-953-51-0124-6

Hard cover, 180 pages

Publisher InTech

Published online 02, March, 2012

Published in print edition March, 2012

Human embryology is now rapidly moving to a new phase due to recent innovation and advances of life science including ES and iPS technology. This new era also directs a difficult challenge for scientists in terms of technological and ethical issues for future human embryology. However, human embryology is difficult to research due to ethics involved in the collection of human materials. This book traces the early history and provides knowledge on demonstration of principles from ancient to the most recent embryo studies amidst the unresolved scientific and ethical issues. We hope this book will help the readers to understand human embryo development better.

\title{
How to reference
}

In order to correctly reference this scholarly work, feel free to copy and paste the following:

Deirdre Zander-Fox and Michelle Lane (2012). The Future of Human Embryo Culture Media - Or Have We Reached the Ceiling?, The Human Embryo, Dr. Shigehito Yamada (Ed.), ISBN: 978-953-51-0124-6, InTech, Available from: http://www.intechopen.com/books/the-human-embryo/the-future-of-embryo-culture-media-orhave-we-reached-the-ceiling-

\section{INTECH}

open science | open minds

\section{InTech Europe}

University Campus STeP Ri Slavka Krautzeka 83/A 51000 Rijeka, Croatia

Phone: +385 (51) 770447

Fax: +385 (51) 686166 www.intechopen.com

\section{InTech China}

Unit 405, Office Block, Hotel Equatorial Shanghai No.65, Yan An Road (West), Shanghai, 200040, China 中国上海市延安西路65号上海国际贵都大饭店办公楼 405 单元 Phone: $+86-21-62489820$

Fax: $+86-21-62489821$ 
(C) 2012 The Author(s). Licensee IntechOpen. This is an open access article distributed under the terms of the Creative Commons Attribution 3.0 License, which permits unrestricted use, distribution, and reproduction in any medium, provided the original work is properly cited. 